\title{
KORELASI TINGKAT STRES DENGAN KUALITAS TIDUR LANSIA
}

\section{CORRELATION BETWEEN STRESS LEVELS AND SLEEP QUALITY ON ELDERLY}

\author{
Ni Putu Rahayu Indra Dewi ${ }^{1}$, Ni Kadek Yuni Lestari ${ }^{2}$, Ni Luh Putu Thrisna Dewi ${ }^{3}$ \\ STIKes Wira Medika Bali123
}

\begin{abstract}
ABSTRAK
Proses menua (aging) adalah proses alami yang dihadapi manusia dimana pada tahap ini terjadi penurunan atau perubahan kondisi fisik, psikologis maupun sosial. Perubahan tersebut dapat mengakibatkan lansia mengalami stres. Stres merupakan suatu keadaan yang diakibatkan oleh perubahan lingkungan dan dianggap menantang, mengancam atau merusak keseimbangan dinamis seseorang. Stres yang tidak ditangani dapat mempengaruhi tidur pada lansia sehingga menyebabkan kualitas tidur pada lansia menjadi buruk. Penelitian ini bertujuan untuk mengetahui hubungan tingkat stres dengan kualitas tidur lansia. Design penelitian ini adalah deskriptif korelasi, jumlah sampel 59 orang lansia yang diambil dengan teknik Purposive Sampling. Pengambilan data dilakukan dengan memberikan kuisioner DASS dan PSQI. Hasil penelitian menunjukkan lansia mengalami stres sedang sebanyak 24 orang $(40,7 \%)$ dan lansia mengalami kualitas tidur buruk sebanyak 19 orang $(42,2 \%)$. Hasil uji Rank Spearman didapatkan nilai $\mathrm{p}$ value $=0,000(\mathrm{p}<a$ $=0,05$ ) yang menunjukkan adanya hubungan yang bermakna (signifikan) antara tingkat stres dengan kualitas tidur lansia di Panti Sosial Tresna Werdha Jara Mara Pati Singaraja. Nilai coefisien correlation sebesar 0,604 dengan arah hubungan positif yaitu semakin tinggi tingkat stres maka kualitas tidurnya semakin buruk. Di sarankan kepada perawat/petugas Panti Sosial Tresna Werdha Jara Mara Pati Singaraja agar mengadakan program khusus yang dapat menngontrol manajamen stres pada lansia, misanya senam otak dan terapi reminiscence.
\end{abstract}

Kata kunci : Lansia, Tingkat Stres, Kualitas Tidur

\section{ABSTRACT}

The aging process is a natural process which happens to human being, where at this stage physical condition, psychology and social change or decrease will happen. The change may cause the elderly undergo stress. Stress is a condition or situation which is caused by environmental change and considered to be challenging, threating or destructing someone's dynamic balance. Stress which is not properly handled may influence the elderly's sleep quality becomes poor. The research is aimed to recognize the correlation between the stress level and elderly's quality sleep. The design of this research is descriptive correlation which the number of sample is 59 elderly which are taken by purposive sampling technique. The data collection was implemented by giving DASS and PSQI Questionnaires. The result of the research shows that most of elderly with medium level of stress are 24 people $(40,7 \%)$ and elferly undergo poor sleep quality are 19 people $(42,2 \%)$. The result of spearman test gains $P$ value $=0,000(p<a=0,05)$ which indicates 
Bali Medika Jurnal.

Vol 7 No 1, 2020: 61-68

ISSN : 2615-7047

DOI: https://doi.org/10.36376/bmj.v7i1

the existence of significant correlation between stress level and Elderly's sleep quality at Panti Sosial Tresna Werdha Jara Mara Pati Singaraja. Coefficient Value is 0, 604 which indicates strong correlation between two variables with the points of positive correlation that the higher level of stress the poorer sleep quality will be. The Nurses/Attendant of Panti Sosial Tresna Werdha Jara Mara Pati Singaraja are suggested to hold or conduct special program which will enable to control the stress management for the elderly for example brain exercise or reminiscence therapy.

Keyword: Elderly, Stress Level, Sleep Quality

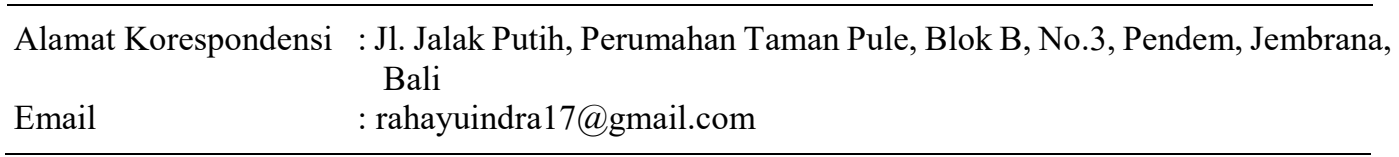

\section{PENDAHULUAN}

Proses menua (aging) adalah proses alami yang dihadapi manusia, dimana pada tahap ini terjadi penurunan atau perubahan kondisi fisik, psikologis maupun sosial. Keadaan itu cendrung berpotensi menimbulkan masalah kesehatan secara fisik maupun kesehatan jiwa pada lanjut usia (Nugroho, 2012). Memasuki usia tua banyak mengalami kemunduran misalnya kemunduran fisik yang ditandai dengan kulit menjadi keriput karena berkurangnya bantalan lemak, rambut memutih, pendengaran berkurang, menglihatan memburuk, gigi mulai ompong, aktifitas menjadi lambat, nafsu makan berkurang, dan kondisi tubuh yang lain juga mengalami kemunduran (Padila, 2013). Menurut World Health Organization (WHO, 2013) lanjut usia dibedakan menjadi 4 yakni usia pertengahan (Middle Age) antara 45-59 tahun, usia lanjut (Elderly Age) antara 60-74 tahun, usia lanjut tua (Old) antara 75-90 tahun, usia sangat tua (Very Old) di atas 90 tahun.

Banyak sekali masalah yang sering dialami oleh usia lanjut, salah satunya adalah stress. Stres dapat diartikan sebagai suatu stimulus yang mengakibatkan ketidakseimbangan fungsi fisiologi dan psikologis. Stres adalah pola reaksi menghadapi stressor yang berasal dari dalam individu maupun dari lingkungannya (Muhith, A \& Siyoto, S, 2016). Dari hasil penelitian Barua, 2011 (dalam Katuuk \& Wowor, 2018) dengan judul penelitian Hubungan Kemunduran Fisiologis Dengan Tingkat Stres Pada Lanjut Usia Di Puskesmas Kakaskasen Kecamatan Tomohon Utara juga didapatkan prevalensi lansia yang mengalami stres di dunia berkisar 4,7$16 \%$.

Menurut hasil penelitian yang dilakukan Dariah \& Okatiranti (2015) didapatkan bahwa stres merupakan salah satu faktor yang mempengaruhi kualitas tidur. Kualitas tidur yang buruk akan berdampak terhadap kesehatan, yang mengakibatkan lansia rentan terhadap penyakit, konfusi, disorientasi, gangguan mood, kurang fresh, menurunnya kemampuan berkonsentrasi dan kemampuan membuat keputusan (Potter \& Perry, 2009). Cuellar et al, 2007 (dalam Potter \& Perry, 2011) menemukan bahwa lebih dari 50\% lansia memiliki gangguan tidur. Dampak lebih lanjut dari kualitas tidur yang buruk akan menyebabkan menurunnya kemandirian lansia dalam melakukan aktivitas sehari-hari yang berujung pada penurunan kualitas hidup pada lansia (Lo \& Lee, 2012). 
Dari hasil studi pendahuluan yang dilakukan pada tanggal 10 Agustus 2019, di Panti Sosial Tresna Werdha Jara Mara Pati Singaraja dengan teknik wawancara dari 10 responden (lansia) didapatkan hasil yang bervariasi satu dengan yang lainnya, 6 responden $(60 \%)$ mengatakan mengalami kesulitan tidur dan sering terbangun di malam hari, hal ini dikarenakan lansia masih mengalami perasaan kesepian, tidak berharga, dan kurang mendapat perhatian dari keluarganya. Sedangkan 4 responden (40\%) mengatakan tidak mengalami masalah tidur seperti sering terbangun di malam hari bahkan insomnia.

\section{METODE PENELITIAN}

Penelitian ini merupakan penelitian kuantitatif. Desain penelitian yang digunakan dalam penelitian ini yaitu desain penelitian deskriptif korelasi dengan pendekatan cross sectional desain korelasi adalah penelitian yang menghubungkan variable yang satu dengan yang lainnya, dan pendekatan cross sectional adalah penelitian yang mendesain pengumpulan datanya dilakukan pada satu titik waktu (at one point in time): fenomena yang diteliti adalah selama satu periode pengumpulan data. Desain penelitian ini digunakan untuk mengetahui adanya hubungan tingkat stres dengan kualitas tidur lansia. Populasi dalam penelitian ini adalah seluruh lansia di Panti Sosial Tresna Werdha Jara Mara Pati Singaraja sebanyak 69 lansia. Sampel dalam penelitian ini berjumlah 59 orang lansia. Pengambilan sampel menggunakan tehnik non probability sampling yaitu purposive sampling. Penelitian ini dilakukan di Panti Sosial Tresna Werdha Jara Mara Pati Singaraja. Penelitian ini dilakukan pada bulan November 2019. Penelitian ini menggunakan instrument penelitian berupa kuesioner DASS dan PSQI. Tehnik analisa data yang digunakan untuk menguji hubungan dalam penelitian ini adalah menggunakan uji statistik Spearman Ranks.

HASIL

HASIL DAN PEMBAHASAN

Tabel 1. Karakteristik Responden

\begin{tabular}{|c|c|c|}
\hline \multirow[t]{2}{*}{ Umur } & \multicolumn{2}{|c|}{ Hasil Penelitian } \\
\hline & Frekuensi & Persentase (\%) \\
\hline $61-70$ & 14 & 23,7 \\
\hline $71-80$ & 30 & 50,9 \\
\hline $81-90$ & 15 & 25,4 \\
\hline Total & 59 & 100 \\
\hline \multirow[t]{2}{*}{ Jenis Kelamin } & \multicolumn{2}{|c|}{ Hasil Penelitian } \\
\hline & Frekuensi & Persentase (\%) \\
\hline Laki-laki & 16 & 27,1 \\
\hline Perempuan & 43 & 72,9 \\
\hline Total & 59 & 100 \\
\hline \multirow[t]{2}{*}{ Pendidikan Terakhir } & \multicolumn{2}{|c|}{ Hasil Penelitian } \\
\hline & Jumlah & Persentase (\%) \\
\hline
\end{tabular}


Bali Medika Jurnal.

Vol 7 No 1, 2020: 61-68

ISSN : 2615-7047

DOI: https://doi.org/10.36376/bmj.v7i1

\begin{tabular}{|c|c|c|}
\hline SD & 14 & 23,7 \\
\hline SMP & 18 & 30,5 \\
\hline SMA & 11 & 18,6 \\
\hline Tidak Sekolah & 16 & 27,1 \\
\hline Total & 59 & 100 \\
\hline \multirow[t]{2}{*}{ Riwayat Pekerjaan } & \multicolumn{2}{|c|}{ Hasil Penelitian } \\
\hline & Jumlah & Persentase(\%) \\
\hline Swasta & 10 & 16,9 \\
\hline Petani/Buruh & 17 & 28,8 \\
\hline Wiraswasta & 16 & 27,1 \\
\hline Tidak Bekerja & 16 & 27,1 \\
\hline Total & 59 & 100 \\
\hline \multirow[t]{2}{*}{ Alasan Tingal di Panti } & \multicolumn{2}{|c|}{ Hasil Penelitian } \\
\hline & Jumlah & Persentase (\%) \\
\hline Kemauan Sendiri & 13 & 22 \\
\hline Kemauan Keluarga & 46 & 78 \\
\hline Alasan Lain & 0 & 0 \\
\hline Total & 59 & 100 \\
\hline \multirow[t]{2}{*}{ Lama Tinggal di Panti } & \multicolumn{2}{|c|}{ Hasil Penelitian } \\
\hline & Jumlah & Persentase (\%) \\
\hline 0-5 Tahun & 39 & 66,1 \\
\hline 5-10 Tahun & 6 & 10,2 \\
\hline$>10$ Tahun & 14 & 23,7 \\
\hline Total & 59 & 100 \\
\hline
\end{tabular}

Berdasarkan karakteristik usia didapatkan dari 59 responden pada penelitian ini didominasi oleh lansia berusia 71-80 tahun yaitu 30 orang lansia (50,9\%). Berdasarkan karakteristik jenis kelamin didapatkan dari 59 responden pada penelitian ini didominasi oleh lansia perempuan yaitu sebanyak 42 orang lansia (72,9\%). Berdasarkan karakteristik dari 59 responden, sebagian besar lansia pendidikan terakhirnya adalah SMP yaitu berjumlah 18 orang lansia $(30,5 \%)$. Berdasarkan karakteristik dari 59 responden, sebagian besar lansia memiliki riwayat pekerjaan sebagai petani/buruh yaitu berjumlah 17 orang lansia $(28,8 \%)$. Berdasarkan karakteristik dari 59 responden, sebagian besar lansia yang tinggal di Panti dengan alasan kemauan keluarga yaitu berjumlah 46 orang lansia (78\%). Berdasarkan tabel 4.2 dari 59 responden, sebagian besar lama tinggal lansia di panti selama 0-5 tahun yaitu berjumlah 39 orang lansia $(66,1 \%)$.

Tabel 2. Tingkat Stres Pada Lansia Di Panti Sosial Tresna Werdha Jara Mara Pati Singaraja

\begin{tabular}{lcc}
\hline \multicolumn{1}{c}{ Tingkat Stres } & \multicolumn{2}{c}{ Hasil Penelitian } \\
\cline { 2 - 3 } & Frekuensi & $\begin{array}{c}\text { Persentase } \\
\mathbf{( \% )}\end{array}$ \\
\hline Normal & 3 & 5,1 \\
Stres Ringan & 9 & 15,3 \\
Stres Sedang & 24 & 40,7 \\
\hline
\end{tabular}


DOI: https://doi.org/10.36376/bmj.v7i1

\begin{tabular}{lcc}
\hline Stres Berat & 20 & 33,9 \\
Stres Sangat Berat & 3 & 5,1 \\
& & \\
\hline Total & 59 & 100 \\
\hline
\end{tabular}

Berdasarkan tingkat stres subyek penelitian didapatkan hasil bahwa tingkat stres pada lansia dengan frekuensi terbanyak adalah kategori stres sedang dengan jumlah 24 orang lansia $(40,7 \%)$ dan stres berat dengan jumlah 20 orang lansia $(33,9 \%)$.

Tabel 3. Kualitas Tidur Pada Lansia Di Panti Sosial Tresna Werdha Jara Mara Pati Singaraja

\begin{tabular}{lcc}
\hline Kualitas & \multicolumn{2}{c}{ Hasil Penelitian } \\
\cline { 2 - 3 } Tidur Pada & Frekuensi & Persentase (\%) \\
Lansia & & \\
\hline Baik & 14 & 23,7 \\
Buruk & 45 & 76,3 \\
\hline Total & 59 & 100 \\
\hline
\end{tabular}

Berdasarkan kualitas tidur subyek penelitian didapatkan hasil bahwa kualitas tidur pada lansia dengan frekuensi terbanyak adalah kategori buruk dengan jumlah 45 orang lansia $(76,3 \%)$. Tabel 4. Hasil Analisis Hubungan Tingkat Stres Dengan Kualitas Tidur
Lansia Di Panti Sosial Tresna Werdha Jara Mara Pati Singaraja

\begin{tabular}{|c|c|c|c|c|c|c|c|c|c|}
\hline \multicolumn{6}{|c|}{ Kualitas Tidur } & \multirow{2}{*}{\multicolumn{2}{|c|}{ Total }} & \multirow{3}{*}{$\begin{array}{c}\text { Koefisien } \\
\text { Korelasi }\end{array}$} & \multirow{3}{*}{$\begin{array}{c}\mathrm{p}- \\
\text { value }\end{array}$} \\
\hline \multirow[t]{2}{*}{ No } & \multirow{2}{*}{$\begin{array}{c}\text { Tingkat } \\
\text { Stres }\end{array}$} & \multicolumn{2}{|c|}{ Baik } & \multicolumn{2}{|c|}{ Buruk } & & & & \\
\hline & & f & $(\%)$ & $\mathbf{f}$ & $(\%)$ & $\mathbf{f}$ & $(\%)$ & & \\
\hline 1 & Normal & 3 & 5.1 & 0 & 0.0 & 3 & 5. & 0,604 & 0,000 \\
\hline 2 & Stres & 6 & 10.1 & 3 & 5.1 & 9 & 15.2 & & \\
\hline 3 & Ringan & 5 & 8.5 & 19 & 32.2 & 24 & 40.7 & & \\
\hline 4 & Stres & 0 & 0.0 & 20 & 33.9 & 20 & 33.0 & & \\
\hline 5 & Sedang & 0 & 0.0 & 3 & 5.1 & 3 & 5.1 & & \\
\hline & Stres & & & & & & & & \\
\hline & Berat & & & & & & & & \\
\hline & Sangat & & & & & & & & \\
\hline & Berat & & & & & & & & \\
\hline & Total & & & & & 59 & $100 \%$ & & \\
\hline
\end{tabular}

Tingkat stres lansia yang paling dominan yaitu stres sedang sebanyak 24 orang $(40,7 \%)$ dengan kualitas tidur buruk Berdasarkan hasil uji Spearman's Rho didapatkan nilai $\mathrm{p}$-value sebesar $0,000(\mathrm{p}<0,05)$, hasil ini menunjukkan ada hubungan yang signifikan antara tingkat stres dengan kualitas tidur lansia di Panti Sosial Tresna Werdha Jara Mara Pati Singaraja. Nilai koefisien korelasi sebesar 0,604 menunjukkan variabel tingkat stres dengan kualitas tidur lansia memiliki 
derajat hubungan yang kuat. Tidak terdapat tanda negatif(-) di depan nilai koefisien korelasi yang menunjukkan bahwa arah hubungan antar variabel terdapat hubungan yang positif artinya semakin tinggi tingkat stres pada lansia maka kualitas tidurnya semakin buruk.

\section{PEMBAHASAN}

Berdasarkan hasil penelitian terhadap 59 responden diperoleh data tingkat stres sedang sebanyak 24 orang lansia $(40,7 \%)$ dan tingkat stres berat sebanyak 20 orang lansia (33,9\%). Secara umum tingkat stes pada lansia di Panti Sosial Tresna Werdha Jara Mara Pati Singaraja dipengaruhi oleh lama tinggal di panti dan alasan tinggal di panti. Hasil penelitian ini didukung oleh teori Schlutz \& Brenner (dalam Dahlan, 2018) yang menyatakan bahwa penempatan lansia di panti werdha mengakibatkan lansia mengalami suatu perubahan social yang dapat menjadi stressor dan diyakini berperan dalam meningkatnya mortalitas, walaupun terkadang penempatan lansia di panti maupun lembaga-lembaga sosial merupakan keinginan lansia itu sendiri atau karena kondisi keluarga. Hasil penelitian ini sejalan dengan penelitian (Indriana et al. (2010), dengan judul Tingkat Stres Lansia di Panti Werdha "Pucang Gading" Semarang, yang menyatakan banyaknya stresor dapat menimbulkan stres pada diri seseorang dan bukan karena stres yang disebabkan dari lingkungan saja tetapi dari dalam diri individu. peneliti berasumsi bahwa masingmasing lansia memiliki tingkat stres yang berbeda-beda, karena stres bersifat subjekif dan dipengaruhi oleh banyak faktor. Kejadian tingkat stres pada lansia di panti juga dipengaruhi oleh kurangnya aktivitas dan kegiatan keseharian mereka.

Berdasarkan hasil penelitian yang dilakukan terhadap 59 responden diperoleh data bahwa mayoritas responden memiliki kualitas tidur buruk yaitu sebanyak 45 orang lansia (76,3\%). Secara umum kualitas tidur buruk pada lansia di Panti Sosial Tresna Werdha Jara Mara Pati Singaraja dipengaruhi oleh usia, lama tinggal di panti dan alasan tinggal di panti. Hasil penelitian ini didukung oleh teori Kozier (2010) yang menyatakan bahwa faktor-faktor yang dapat mempengaruhi tidur adalah faktor usia, lingkungan, kelelahan, gaya hidup, stress psikologis, alkohol dan stimulan, diet, merokok, motivasi, sakit, dan medikasi. Penelitian ini sejalan dengan penelitian Kumar \& Ratep (2017) dengan judul Kualitas Tidur Pada Geriatri di Panti Sosial Tresna Werdha Wana Sraya didapatkan hasil sebagian besar lansia memiliki kualitas tidur buruk sebanyak 63,3\%, mayoritas geriatric yang memiliki kualitas buruk disebabkan oleh beberapa faktor diantaranya adalah lingkungan, masalah keluarga, dan masalah pertemanan. Peneliti berasumsi bahwa pada lansia memiliki pola tidur yang berbeda dengan remaja. Tingginya masalah tidur yang terjadi pada lansia memerlukan penanganan yang sesuai untuk meningkatkan pemenuhan kebutuhan tidur. Pemenuhan kebutuhan tidur setiap orang berbeda-beda dan terlihat dari kualitas tidurnya.

Berdasarkan penelitian yang telah dilakukan didapatkan hasil analisis data antara tingkat stres dengan kualitas tidur lansia didapat $p=0,000(p<a=0,05)$ sehingga Ho ditolak dan Ha diterima. Dapat dikatakan secara statistik bahwa terdapat hubungan yang bermakna (signifikan) antara tingkat stres dengan kualitas tidur lansia di Panti Sosial Tresna Werdha Jara Mara Pati Singaraja. Berdasarkan hasil analisis terhadap 59 orang lansia diperoleh sebanyak 24 orang lansia (40,7\%) mengalami stres sedang dan 20 orang lansia (33,9\%) mengalami stres berat. Hasil analisis juga menunjukkan sebanyak 45 orang lansia $(76,3 \%)$ mengalami kualitas 
tidur buruk. Dari hasil penelitian tersebut sesuai dengan pendapat Sofiana (2014) bahwa stres berpengaruh pada kualitas tidur seseorang. Teori tersebut diperkuat dengan penelitian yang dilakukan Hidayat (2016) yang berjudul "Hubungan Tingkat Stres Dengan Kualitas Tidur Lansia Di Desa Condong Catur Depok Sleman" dengan hasil penelitian menunjukkan bahwa ada hubungan tingkat stres dengan kualitas tidur lansia yaitu diperoleh nilai $p$ value $=0,000(p<0,05)$ dengan hasil penelitian menunjukkan sebagian besar responden mengalami stres ringan sebanyak 28 orang lansia (40\%) dan sebagian besar mengalami kualitas tidur buruk sebanyak 41 orang lansia (58\%). Dari hasil tersebut peneliti dapat simpulkan bahwa lansia yang mengalami stres akan berpengaruh pada kualitas tidurnya begitu pula sebaliknya, jika lansia yang tidak mengalami stres cenderung tidak terjadi gangguan pada kualitas tidurnya.

Peneliti berasumsi bahwa adanya hubungan tingkat stres dengan kualitas tidur lansia, sebagian besar lansia belum mengetahui bahwa stres dapat mengakibatkan buruknya kualitas tidur. Lansia hanya berpendapat bahwa mereka memang sudah biasa memiliki kualitas tidur yang buruk dan tidak berupaya mengatasinya. Pihak petugas kesehatan yang menangani lansia di Panti Sosial Tresna Werdha Jara Mara Pati Singaraja juga belum melakukan pemeriksaan psikologis maupun kualitas tidur, sehingga lansia belum tahu apabila mereka mengalami masalah psikologis atau memiliki kualitas tidur yang buruk.

\section{Simpulan}

\section{SIMPULAN DAN SARAN}

Berdasarkan hasil penelitian, didapatkan hasil adanya hubungan antara tingkat stes dengan kualitas tidur lansia, faktor yang mempengaruhi tingkat stres paling dominan yaitu faktor lama tinggal di panti dan alasan tinggal di panti. Hal tersebut juga mempengaruhi kualitas tidur lanisa yang disebabkan oleh faktor usia, lama tinggal di panti dan alasan tinggal di panti.

\section{Saran}

Kepada institusi pendidikan diharapkan penelitian ini dapat dijadikan bahan refrensi, dan menambah pengetahuan mahasiswa dalam bidang keperawatan gerontik khususnya mengenai tingkat stres dengan kualitas tidur lansia. Kepada lansia diharapkan lansia yang berada di Panti Sosial Tresna Werdha Jara Mara Pati Singaraja dapat mengontrol manajemen stres guna memperbaiki kualitas tidur maupun kualitas hidup lansia. Kepada perawat/Panti Sosial Tresna Werdha Jara Mara Pati Singaraja diharapkan pada perawat/petugas di Panti Sosial Tresna Werdha Jara Mara Pati Singaraja agar mengadakan program khusus yang dapat mengontrol manajemen stres pada lansia, misalnya senam otak dan terapi reminiscence. Kepada peneliti selanjutnya diharapkan penelitian ini dapat menjadi tahap awal untuk penelitian selanjutnya yang terkait dengan tingkat stres dan kualitas tidur lansia. Penelitian lanjutan perlu dilakukan untuk menemukan hasil yang lebih maksimal. Penelitian lanjutan dapat berupa mencari faktor-faktor lain yang dapat mempengaruhi kualitas tidur lansia. 


\section{DAFTAR PUSTAKA}

Dahlan, K. A. (2018). Kesehatan Lansia Kajian Teori Gerontologi dan Pendekatan Asuhan Pada Lansia. Intimedia.

Dariah, E. D., \& Okatiranti, O. (2015). Hubungan Kecemasan dengan Kualitas Tidur Lansia di Posbindu Anyelir Kecamatan Cisarua Kabupaten Bandung Barat. Jurnal Keperawatan BSI, 3(2).

Hidayat, H. A. N. (2016). Hubungan tingkat stres dengan kualitas tidur lansia di dusun Joho Desa Condong Catur Depok Sleman. STIKES Jenderal A. Yani Yogyakarta.

Indriana, Y., Kristiana, I. F., Sonda, A., \& Intanirian, A. (2010). Tingkat stres lansia di panti wredha "pucang gading" semarang. Jurnal Psikologi Undip, 8(2).

Katuuk, M., \& Wowor, M. (2018). Hubungan Kemunduran Fisiologis Dengan Tingkat Stres Pada Lanjut Usia Di Puskesmas Kakaskasen Kecamatan Tomohon Utara. Jurnal Keperawatan, 6(1).

Kozier. (2010). Buku Ajar Praktik Keperawatan Klini (5th ed.). EGC.

Kumar, V. A. H., \& Ratep, N. (2017). Kualitas tidur pada geriatri di panti jompo tresna wana seraya, Denpasar-Bali. Directory Of Open Access Journals. Vol. 8 No. 2: 151, 154.

Lo, C. M. H., \& Lee, P. H. (2012). Prevalence and impacts of poor sleep on quality of life and associated factors of good sleepers in a sample of older Chinese adults. Health and Quality of Life Outcomes, 10(1), 72.

Nugroho. (2012). Keperawatan Gerontik \& Geriatrik (3rd ed.). EGC.

Padila. (2013). Asuhan Keperawatan Penyakit Dalam. EGC.

Potter, P. A., \& Perry, A. G. (2009). Fundamental keperawatan (7th ed.). Salemba Medika.

Potter, P. A., \& Perry, A. G. (2011). Buku Ajar Fundamental Keperawatan. EGC. WHO. (2013). Mental Health and Older Adults. 